\title{
Bases do Nacionalismo Econômico em Friedrich List
}

\section{Bases of Economic Nationalism in Friedrich List}

Flávio dos Santos Oliveira*

\begin{abstract}
Resumo: O artigo propõe uma reconstrução histórica do pensamento econômico de Friedrich List, ressaltando a sua formação como intelectual e burocrata. Destaca-se a contribuição do autor alemão na consolidação do Sistema Americano de Economia Política, bem como a influência do Historicismo e do Idealismo Alemão na construção do seu método histórico analítico. Ressalta-se ainda a importância da Zollverein e do Sistema Nacional de Transporte Ferroviário propostos por List na aceleração do processo de Unificação da Alemanha.
\end{abstract}

Palavras-chave: União aduaneira. Protecionismo. Sistema americano. Economia nacional. Economia política.

\begin{abstract}
This paper proposes a historical reconstruction of Friedrich List's economic thought, highlighting its formation as an intellectual and bureaucrat. The paper also outlines the German author's contribution to the consolidation of the American System of Political Economy, as well as the influence of Historicism and German Idealism in building his analytical historical method. It is noteworthy the importance of Zollverein and the National System of Railroad transport proposed by List in accelerating Germany's unification process.
\end{abstract}

Keywords: Customs union. Protectionism. American system. National economy. Political economy.

JEL Classification: B10; B15; B31.

\section{Introdução}

Georg Friedrich List é reconhecido como um dos principais representantes do protecionismo e da teoria do desenvolvimento econômico nacional (BOIANOVSKY, 2011, p. 1; CHANG, 2007b, p. 3). As ideias fundamentais do autor alemão, contudo, tiveram alcance muito mais amplo. Sua teoria das forças produtivas e seu conceito de capital mental, por exemplo, assentaram as bases últimas de uma concepção imaterial da economia e da civilização. Além disso, pode-se arguir que a sua obra foi determinante para acelerar o processo de Unificação da Alemanha. Antes de List, o conceito de nação alemã vinha sendo construído de um ponto de vista, sobretudo, histórico-cultural e político. Nesse sentido, merecem destaque

Doutorando do Programa de Pós-Graduação em História Social das Relações Políticas da Universidade Federal do Espírito Santo (UFES). E-mail: oliveiraflavio3192@yahoo.com 
as contribuições de Johann Gottfried von Herder, ${ }^{1}$ para quem a nação seria uma unidade orgânica, cultural e linguística que manteria unidos os diferentes indivíduos não somente por meio de ideias, inclinações e modos de vida comuns, mas também por meio de leis e instituições transmitidas às outras gerações por intermédio da linguagem, dos hábitos e da educação, dando-lhes sua forma específica e plural (HERDER, 2007, p. 54-55; LEVINGER, 2000, p. 48). Por outro lado, Johann Gottlieb Fichte, um dos maiores expoentes do Idealismo Alemão, construiu seu conceito de nação alemã a partir da autorrepresentação da völkisch, isto é, a consciência da identidade comum de um suposto "caráter fundamental" que se origina, sobretudo, da autenticidade de sua língua. ${ }^{2}$

Apesar da originalidade dessas concepções de nação, elas não foram suficientes para promover a unificação da Alemanha. Após a dominação napoleônica e o Congresso de Viena, o vasto território que compreendia o antigo Sacro Império Germânico foi reunido em 33 Estados Alemães, com destaque para Áustria, Prússia, Saxônia, Baden, Württemberg, entre outros, que guardavam zelosamente seus direitos de autonomia, sua independência e, sobretudo, o controle das inúmeras aduanas nos rios e estradas que cortavam seus domínios. Com efeito, a unificação da Alemanha foi levada adiante não apenas por conta de fatores culturais, mas principalmente em virtude das novas necessidades oriundas da expansão do capitalismo. Nesse sentido, merece destaque a intensa atividade política e intelectual de Friedrich List em seu esforço de promover a unidade econômica e política da Alemanha por meio da Zollverein e seu sistema nacional de transporte ferroviário. Decerto, List percebeu que diante do fortalecimento da Inglaterra como nação industrialmente desenvolvida e a reafirmação da Áustria e da Rússia como potências imperiais após o Congresso de Viena, somente a supressão das barreiras políticas e econômicas que até então dividiam os territórios germânicos poderia levar à superação da fragmentação política e do retardo técnico-industrial dos estados alemães.

A obra mais importante de Friedrich List é, sem dúvida, o seu Sistema Nacional de Economia Política (1841) (Das Nationale System der Politischen Oekonomie), o

1 Graças à sua múltipla e diversificada produção intelectual, Johann Gottfried von Herder ocupa lugar de destaque na formação do pensamento moderno alemão, sendo considerado não somente o precursor do Historicismo e da Volksgeist, mas também o porta-voz do nacionalismo cultural alemão (BENTO, 2010, p. 15; BERLIN, 1976, p. 145).

2 Segundo Fichte (2009), o "caráter fundamental" do alemão deriva essencialmente de seu habitat, sua raça, sua memória, sua religião e, sobretudo, sua língua. Dito de outro modo, sua índole peculiar origina-se do fato de os primeiros alemães terem ficado no habitat natural dos seus antepassados. Esse relativo isolamento constituiu sua memória como um legado e sua raça como expressão da cultura, isto é, uma cultura de liberdade que permite aos alemães o acesso ao suprassensível. Além disso, com a Reforma, sua religião se desenvolveu em um grau mais elevado de liberdade, e sua língua, por não ter sido misturada com a de outros povos, tornou-se a fonte de sua indelével identidade e superioridade em relação às outras tribos germânicas que em seu processo de sincretismo assimilaram a já decrépita língua latina e, por isso, sucumbiram ante a latinidade (FICHTE, 2009, p.48-73; CHEVALLIER, 1995, p. 238). 
qual, conforme indicado no título, trata da dimensão nacional do seu pensamento econômico e político, sendo considerado a expressão mais cabal do "nacionalismo econômico" no século XIX. Essa obra foi precedida, entretanto, por duas versões mais curtas, a saber, os Outlines of American Political Economy (Esboços de Economia Política Americana, 1827), escritos durante a sua estadia nos Estados Unidos, entre 1825 e 1832, e o Système Naturel D'Économie Politique (Sistema Natural de Economia Política, 1837), como resposta à uma questão proposta pela Academia Francesa de Ciência Moral e Econômica³ (BOIANOVSKY, 2011, p. 4).

Com efeito, far-se-á, no que segue, uma reconstrução histórica do pensamento econômico de Friedrich List, destacando-se a sua formação intelectual e, sobretudo, a sua intensa atividade política em prol da unificação da Alemanha. Para tanto, o artigo encontra-se divido em seis seções, a primeira sendo a presente introdução. A segunda trata brevemente de aspectos essenciais da carreira de List como burocrata e político, até o seu exílio nos Estados Unidos. A terceira seção põe em evidência a contribuição de List, por meio de seus Outlines of American Political Economy, para a consolidação da escola de pensamento econômico posteriormente denominada Sistema Americano de Economia Política (The American System). Na quarta seção, será discutida a influência do Historicismo e do Idealismo Alemão na formação List, como forma de lançar luz sobre a polêmica acerca da matriz do pensamento listiano. Por fim, examina-se a influência de List na constituição da Zollverein (União Aduaneira dos Estados Alemães) e como o seu proposto sistema de transporte ferroviário desencadeou significativo avanço na unificação político-econômica da Alemanha, seguido pelas considerações finais.

3 Quando List chegou à França no final de outubro de 1837, ele aparentemente não tinha a intenção de retomar seus estudos sobre economia. Durante os quatro anos anteriores, ele havia tentado fomentar o progresso da construção ferroviária na Alemanha e havia sido particularmente ativo na promoção da ferrovia entre Leipzige Dresden. No entanto, decepcionado com seu fracasso em garantir a diretoria em uma empresa ferroviária, ele deixou a Alemanha para se estabelecer em Paris, onde esperava despertar o interesse do governo francês em seus projetos para a construção de ferrovias na França. Logo após sua chegada em Paris, List soube que a Academia de Ciências Morais e Políticas estava oferecendo prêmio para o tratado que respondesse à pergunta: caso um país proponha a introdução do livre comércio ou então modificar as suas tarifas, quais fatores deveriam ser levados em conta de modo a reconciliar, da maneira mais justa possível, os interesses de produção com os dos consumidores? O ensaio de List sobre o Sistema Natural de Economia Política explicou como, por estimular as suas forças produtivas, um país predominantemente agrário poderia desenvolver novas indústrias e elevar o padrão de vida de seu povo. Os juízes decidiram que nenhum dos ensaios era digno do prêmio, mas consideraram o trabalho de List uma das três obras mais notáveis. List ficou desapontado e, em setembro de 1838, escreveu a Georg von Cotta afirmando sua intenção de reformular e ampliar o seu ensaio para colocá-lo em forma adequada para publicação (HENDERSON, 2006, p. 83). 


\section{Despertar de uma ldeia}

List nasceu a 6 de agosto de 1789, em Reutlingen, cidade livre imperial situada ao sul de Stuttgart. Em 1802, quando List tinha apenas doze anos, Reutlingen se tornou a sede do distrito administrativo de Württemberg por meio do decreto do Duque Friedrich Wilhelm Karl. Como o ducado de Württemberg foi elevado à condição de reino em 1806, urgia fundir as administrações governamentais dos novos territórios ${ }^{4}$ (WENDLER, 2013, p. 7). Tal necessidade pode ter convencido List e seus pais de que aí se configurava ótima oportunidade de ascensão profissional. ${ }^{5}$ Após adquirir experiência prática em administração pública e exímia formação acadêmica em jurisprudência na Universidade de Tübingen, ${ }^{6}$ List foi nomeado, em 1816, primeiro professor de Administração e Política (Staatspraxis und Saatswissenschaft) na Universidade de Tübingen, pelo então ministro da cultura Karl Freiherr von Wangenheim (LEVI-FAUR, 2012, p. 156).

Ao mesmo tempo em que lecionava em Tübingen, List escrevia copiosamente para diversos jornais como o Württembergische Archive (Arquivo de Württenberg), ${ }^{7}$ o Volksfreund aus Schwaben (Amigo da Nação da Suábia), e para

$4 \quad$ Até o ano de sua desintegração em 1806, os territórios que compreendiam a Europa Central constituíam o Sacro Império Romano Germânico (Heiliges Römisches Reich Deutscher Nation), uma instituição política e religiosa composta por mais de trezentas entidades, incluindo independentemente os domínios eclesiásticos, os territórios imperiais, a gleba nobiliárquica imperial etc., sendo que os maiores e mais poderosos domínios situavam-se nas porções norte e leste do império, com a desvantagem, no entanto, de serem notavelmente menos integrados politicamentese comparados com os menores e mais numerosos territórios situados nas regiões sul e oeste. Ali alguns domínios não eram mais do que vilas e pequenas cidades livres imperiais com número escasso de habitantes (ROWE, 2009, p. 55; ZANG, 1994, p. 5-6; FORREST; WILSON, 2009, p. 5). O pai de Friedrich List, Johannes List (1746-1813), foi curtidor respeitável que, além de mestre de sua guilda, vice-magistrado e senador, ocupou vários cargos públicos na cidade. August Merkh, amigo de Friedrich List e mais tarde magistrado em Reutlingen, referiu-se ao pai de Friedrich List como um cidadão sensível, afável e honesto (WENDLER, 2013, p. 1).

6 List ingressou à administração pública primeiro como aprendiz em Blaubeuren, e depois, após passar no exame e exercer o ofício de assistente comissário de alfândega em Schelklingen perto de Ulm, veio a ocupar, em seu vigésimo terceiro ano, um posto na burocracia de Tübingen (HIRST, 1909, p. 3). Posteriormente, ele ascendeu a um grau superior na hierarquia do Departamento da Chancelaria de Tübingen, ingressando, em seguida, no Ministério da Fazenda Real de Württemberg, onde assumiu um cargo como substituto na Secretaria da Fazenda nas cidades de Wiblingen e Ulm. Logo depois, List tornou-se assessor de finanças e contabilidade, e em 1816, foi promovido a Secretário do Ministério do Departamento de Governo Local e inspetor-chefe geral de contas (DAAST $\varnothing$ L, 2011, p. 21).

7 Após a guerra napoleônica, a constituição da nova Federação Alemã estabeleceu que cada estado devia teruma constituição e uma assembleia eleita. A fim de evitar que os seus inimigos desafiassem os seus direitos, seu novo título e seus novos territórios, o rei Friedrich I de Württemberg consentiu em conceder uma nova constituição ao seu reino (HENDERSON, 2006, p. 9). A nova Constituição, que continha elementos liberais como o resultado de longas negociações, foi promulgada pelo Duque de Reischach, Ministro do Interior, em 15 de março de 1815. No entanto, ela garantia apenas parcialmente direitos governamentais para os estados, acarretando, assim, grande insatisfação. List abordou esse conflito em uma petição que apresentou seus pontos de vista e externou suas expectativas liberais e democráticas sobre a nova Constituição. Mais convencido do que nunca da necessidade de uma reforma, em 1816, ele fundou o "Württembergische Archive", 
a Deutsche Handels- und Gerwerbeverein (Revista Industrial e Comercial da Alemanha). Em seus textos da época, ele não tratou apenas de temas ligados às reformas, mas também, contrariando o pensamento predominante da época, colocou em dúvida a validade universal do livre-comércio, defendendo uma política econômica nacional em detrimento de uma economia cosmopolita ${ }^{8}$ (SCHUMPETER, 1964, p. 150). Eleito deputado na Assembleia representativa de Württemberg, em 1819, List iniciou intensa campanha em defesa da indústria nacional e da moralização administrativa. Suas atividades, contudo, provocaram seus adversários e deram-lhes pretextos para exigir sua demissão da cátedra, sob a alegação de que sua postura era imprópria para um funcionário público e ocupante de um cargo político (DAAST ØL, 2011, p. 24). Além disso, uma vez que muitas de suas ideias reformistas foram impressas e distribuídas na forma de panfletos, List foi preso e sentenciado por sedição (FREEMAN; BOWNEN, 2008, p. 65).

List foi condenado a dez meses de prisão (HENDERSON, 2006, p. 64). Ele, contudo, logrou fugir para a França, onde se encontrou com o general Lafayette, ${ }^{9}$ que o exortou a ir para os Estados Unidos. Ao ingressar sem autorização em Stuttgart, porém, em abril de 1824, List foi preso e enviado para a prisão de Hohenasperg, onde ficou detido por cinco meses, somente deixando o cárcere em janeiro de 1825 . No dia 26 de abril de 1825, List migrou para os Estados Unidos com sua família, portando passaporte em que constava ser a sua jornada ao novo país para propósito exclusivo de pesquisa e estudos (HIRST, 1909, p. 32).

Depois de umaviagem tempestuosacom duração de seissemanas, List e sua família desembarcam nos Estados Unidos, dirigindo-se diretamente à Filadélfia. Além da presença de seu amigo, general Lafayette, outra razão a levar a família List para a região foi o grande número de alemães vivendo na área, especialmente nos condados a noroeste do Estado da Pensilvânia. ${ }^{10}$ Durante os três meses em que

jornal voltado para a reforma constitucional e administrativa, do qual se tornou editor-chefe. Isso marca o início de sua carreira jornalística como editor, publicista, coeditor e redator de cerca de dez revistas nacionais e estrangeiras, em que em publicou um total de mais de 700 artigos sobre diversos assuntos (WENDLER, 2013, p. 12).

8 List recordaria que por muitos anos foi discípulo fiel de Smith e Jean-Baptiste Say, ao mesmo tempo que zeloso professor da doutrina clássica, só mudando de opinião em virtude dos resultados positivos do bloqueio continental para a indústria alemã, e dos efeitos danosos subsequentes ao retorno do livre mercado após a queda de Napoleão. A proteção parcial contra a competição inglesa, segundo explicou List em seu Sistema Nacional de Economia Política, desencadeou progresso admirável não apenas nos diferentes setores da indústria alemã, mas também fez florescer todos os ramos da agricultura. Por isso, "quaisquer que sejam as alegações dos teóricos, particularmente dos ingleses, contra o bloqueio, é incontestável [...] que, como resultado daquele bloqueio, as manufaturas alemãs de toda espécie, pela primeira vez, começaram a registrar progresso importante; que somente então se tornou generalizada e bem-sucedida a criação mais aperfeiçoada de ovelhas (iniciada algum tempo antes); que somente então se trabalhou na melhoria dos meios de transporte" (LIST, 1909, p. 173; LIST, 1983, p. 4-64).

9 O encontro com o Marquis de Lafayette foi orquestrado por um amigo paternal deList, o editor Johann Friedrich Cotta (1764-1832).

10 Em 1816 e 1817, Württemberg experiementou um período de escassez como não se tinha notícia 
viajou com o Marquis Lafayette, List foi apresentado aos mais ilustres personagens políticos da época como John Quincy Adams, Henry Clay, Daniel Hamilton, Charles Irgensoll, Andrew Jackson, Ralph Waldo Emerson, entre outros (HENDERSON, 2006, p. 68; BELL, 1942, p. 59).

Após mal sucedida iniciativa como fazendeiro, List tornou-se editor deum jornal germânico-americano intitulado Readinger Adler (Águia Leitora) ${ }^{11} \mathrm{em}$ agosto de 1826 (EARLE, 1943, p. 431). Por meio dessa ocupação, ele inseriu-se ativamente nas questões políticas e econômicas da Pensilvânia, cidade com grande contingente de imigrantes alemães. Sua familiaridade com as questões de economia política e outros assuntos europeus, bem como seu contato com importantes estadistas, tanto na Europa como na América, conferiu-lhe projeção incomum para a maioria dos editores da época, de modo que seus artigos e demais trabalhos foram publicados em todo o país. Em pouco tempo, List tornou-se um dos jornalistas mais importantes em solo americano, participando ativamente dos grandes debates acerca das questões tarifárias no país. ${ }^{12}$

\section{Friedrich List e o Sistema Americano}

Quando List desembarcou nos Estados Unidos, estava em processo de consolidação uma escola de pensamento econômico que viria a ser posteriormente denominada Sistema Americano (The American System). Essa escola baseava-se, sobretudo, no Report on Manufactures: Communicated to the House of Representatives de Alexander Halmiton, o Secretário do Tesouro Americano (1789-1795), que defendia o uso de tarifas protecionistas como forma não apenas de proteger as indústrias nascentes, mas também de criar um mercado interno e um banco nacional para garantir a estabilidade monetária (DAASTØL, 2011, p. 56; CHANG, 2007a, p. 25; 2007b, p. 33-34; HUGHES, 1990, p. 154). O apoio para o "Sistema Americano" vinha principalmente dos fabricantes de lã e ferro de New England e Pennsylvania, enquanto a oposição originava-se nos plantadores de algodão e

desde a Idade Média. Os anos anteriores tinham sido frios e chuvosos, o que levou à quebra da safra. Estoques de alimentos foram esgotados. Por causa disso, a população sofreu como aumento extremo dos preços. Fome e miséria foram generalizadas e numerosas empresas faliram. Perante tal situação, muitas pessoas não tiveram outra opçãoa não ser vendertudo o que possuíameemigrar para os Estados Unidos (WENDLER, 2013, p. 14).

11 O Readinger Adler era um jornal publicado toda terça-feira e conhecido popularmente como a "Berks County Bible", com grande influência na Pensilvânia na época. Fundado em 1798, este jornal em língua alemã teve cerca de 2.500 assinantes até 1826.

12 Durante o período das guerras napoleônicas, as manufaturas têxteis americanas prosperaram sobremaneira, pois foram protegidas da concorrência externa. Quando a paz foi restabelecida em 1815, porém, os mercados americanos viram-se novamente abarrotados de produtos ingleses, o que impeliu os manufatores domésticos a reivindicar a defesa da indústria nascente junto ao Congresso, gerando o intenso debate que se estenderia até meados do século XIX (HUGHES, 1990, p. 154). 
de tabaco do Sul (HENDERSON, 2006, p. 70). Inaugurada por Hamilton e depois desenvolvida por Daniel Raymond, Mathew Carey, John Rae, entre outros, um dos maiores legados dessa escola foi destacar o abismo técnico, industrial e material entre a Europa e a América.

Nos Estados Unidos, a mais ativa organização favorável à proteção da indústria, a saber, a "Sociedade da Filadélfia para a Promoção da Indústria Nacional" (The Philadelphia Society for the Promotion of National Industry), posteriormente, em 1820, denominada "Sociedade de Pensilvânia para a Promoção das Manufaturas e Artes Mecânicas" (Pennsylvania Society for the Promotion of Manufactures and Mechanic Arts), foi fundada por Hamilton para participar ativamente na agitação, panfletagem, patrocínio e proteção da indústria nacional (BELL, 1942, p. 66). Quando List chegou à Filadélfia, essa sociedade era regida por Mathew Carey e pelo então vice-presidente Charles Jared Ingersoll (EARLE, 1943, p. 431), o qual ficou tão impressionado com List que não só lhe pediu para participar da Convenção Nacional dos Protecionistas em Harrisburg, mas também para submeter seus escritos sobre o protecionismo ao National Gazette, os quais foram publicados na forma de doze cartas entre agosto e novembro de 1827, sob o título de Outlines of American Political Economy (FREEMAN, 1997, p. 95). Logo na primeira carta endereçada a Charles Ingersoll, List declara o seu objetivo maior.

Confino os meus esforços, portanto, exclusivamente à refutação da teoria de Adam Smith e companhia, cujos erros fundamentais não têm sido entendidos tão claramente como deveriam ser. É esta teoria, senhor, que fornece aos detratores do Sistema Americano os meios intelectuais de sua oposição (LIST, 1909, p. 148, tradução nossa).

A fim de contestar a visão cosmopolita ${ }^{13}$ apregoada por Smith e a ortodoxia liberal clássica, ${ }^{14}$ List concebe e desenvolve sua ideia de economia nacional. Antes dele, no entanto, Daniel Raymond, em seus Thoughts on Political Economy: A Theory of Productive Power (1821), já havia proposto uma distinção entre economia individual e economia nacional. Em oposição à escola inglesa, ele afirma que a riqueza nacional é algo muito diferente do que a soma total da riqueza individual, e que um incremento da riqueza de uma classe de cidadãos não necessariamente implica um aumento igual da riqueza nacional. Além disso, Raymond chama a

13 Em linhas gerais, o cosmopolitismo baseia-se na crença de que o mundo constitui uma grande pólis e que todos os seres humanos compartilham de certas características essenciais que os unem ou deveriam uni-los em uma ordem global que transcende todas as fronteiras nacionais (KLEINGELD, 1999, p. 505).

14 Em 1789 aparecia na Filadélfia a primeira edição americana de A Riqueza das Nações. A segunda e a terceira reimpressão apareceram em Hartford em 1811 e 1818, respectivamente. Em 1819, apenas dois anos após a sua aparição na Inglaterra, o livro Princípios de Economia Política e Tributação de Ricardo foi reimpresso em Georgetown, e uma tradução de Say apareceu em 1821, sendo rapidamente seguida por uma segunda edição (NEILL, 1897, p. 11). 
atenção para necessidade de se entender o conceito de nação como algo bastante distinto dos indivíduos que a compõe (RAYMOND, 1821, p. 445). De fato, ele sugere que o grande equívoco de Smith e sua escola foi ter confundido os interesses de um indivíduo ou uma classe com os interesses da nação como um todo. Por conseguinte, não é província da economia política estudar como os valores são criados e aumentados ou como os indivíduos e classes podem adquirir riqueza, mas sim estudar como o governo pode melhor legislar no sentido de garantir maior bem-estar para todos os cidadãos igualmente (NEILL, 1897, p. 28-30).

Por outro lado, List sugere ser a nação o medium entre os indivíduos e a humanidade. Trata-se, portanto, de uma comunidade de indivíduos que possui governo, leis, instituições, interesses e história comuns, constituindo um só corpo livre e independente que segue apenas os seus ditames, sendo dotada de prerrogativas para regular os interesses dos indivíduos a fim proporcionar maior segurança coletiva em relação a outras nações. Nesse sentido, o objeto da economia desse corpo não deve ser apenas a riqueza como um fim em si mesmo, mas principalmente o poder, pois a riqueza nacional é aumentada e assegurada pelo poderio da nação, ao passo que o poderio nacional é aumentado e assegurado pela riqueza nacional. De fato, argumenta List, os indivíduos podem ser muito ricos; mas se a nação é destituída de poder para protegê-los, eles podem perder em um dia não apenas a riqueza que adquiriram ao longo de anos, mas também seus direitos, liberdade e independência (LIST, 1909, p. 162).

Sem a intervenção do poder nacional não há segurança, não há confiança no dinheiro cunhado, nos pesos e medidas; não há segurança para os portos marítimos, nem para o comércio de além mar. A ausência do poder nacional acarreta, outrossim, insegurança para os cidadãos em portos e países estrangeiros. Além disso, não há títulos de terra, patentes, direitos de autoria, canais, portos, ferrovias e nenhuma estrada nacional (LIST, 1909 [1827], p. 214; FREEMAN, 1997, p. 95). Desse modo, List salienta, na segunda carta ao National Gazette, a necessidade de intervenção do Estado para o benefício da nação e enumera algumas das responsabilidades do governo.

O Governo, [...], não só temo direito, mas é seu dever promover todas as coisas que podem aumentar a riqueza e o poder da nação, se este objeto não pode ser efetuado pelos indivíduos. Por isso, é seu dever proteger o comércio com uma Marinha, porque os comerciantes não podem se proteger; por isso, é seu dever proteger o negócio do comércio por leis de navegação, [...], a agricultura e todas as outras indústrias por meio de estradas, pontes, canais, ferrovias, e as novas invenções por meio de leis de patentes, de modo que as fábricas devem ser erguidas por direitos de proteção, se o capital estrangeiro e a habilidade impedir o indivíduo de realizá-los (LIST, 1909, p. 164, tradução nossa). 
Em sua sexta carta, List apresenta uma distinção entre Economia Individual e Economia Política. Contestando a ideia smithiana segundo a qual os indivíduos, na promoção dos seus interesses, beneficiam toda a nação, List sugere que esse princípio seria verdadeiro somente se o interesse dos indivíduos e o interesse nacional nunca estivessem em oposição. Mas não é isso que acontece de modo geral. $\mathrm{Na}$ verdade, um país pode ter homens extremamente ricos, e ser extremamente pobre quando inexiste uma distribuição razoável da riqueza (LIST, 1909, p. 213). Nesse sentido, List afirma:

Um indivíduo provisiona apenas para seus propósitos pessoais e familiares, ele raramente se importa com os outros ou a sua posteridade; seus meios e pontos de vista são restritos, raramente ultrapassando o seu círculo de negócios privados; sua indústria está confinada pelo estado da sociedade em que vive. Uma nação provisiona para as necessidades sociais da maioria de seus membros, na medida em que os indivíduos não podem satisfazer esses desejos por seus esforços privados; ela fornece não apenas para o presente, mas para as gerações futuras; não só para a paz, mas para a guerra; seus pontos de vista são estendidos não apenasa o longo de todo o espaço de terra que possuem, mas ao longo de todo o globo (LIST, 1909, p. 212, tradução nossa).

Contrariando a concepção de riqueza baseada no valor de troca, List explica que a riqueza da nação está intrinsecamente relacionada à sua força produtiva, isto é, a resultante da interação entre o capital material e as habilidades dos seus cidadãos, de sua indústria e iniciativa (FREEMAN; BOWEN, 2008, p. 56; LEVI-FAUR, 1997, p. 361). A partir de sua teoria das forças produtivas, List define então três tipos distintos de capitais, a saber: (i) o capital natural; (ii) o capital intelectual e, (iii) o capital material, sendo que a produtividade deste último depende dos dois primeiros, ou seja, da fertilidade da terra e da disponibilidade de recursos minerais no primeiro caso, e especialmente, da habilidade, formação e destreza do povo, dos avanços da ciência e da tecnologia, do sistema educacional, de transporte e de comunicação no tocante ao capital intelectual (BOIANOVSKY, 2011, p. 5).

Segundo List, o grande erro dos economistas liberais clássicos foi terem tratado exclusivamente dos efeitos das trocas materiais. Por conseguinte, como esses teóricos confundiram princípios cosmopolíticos com princípios políticos, eles não lograram apreender por inteiro o objeto da economia política. Este objeto não consiste propriamente em trocar matéria por matéria, como acontece na economia individual e cosmopolita, particularmente nos negócios de um comerciante, mas sim em aumentar as forças produtivas da nação (LIST, 1909, p. 187). A fim de refutar a afirmação de que seria muito dispendioso sacrificar parte do lucro da nação para adquirir força produtiva futura, List sugere que de nada adiantaria uma nação dispor de quedas d'áqua, madeira, lã e tudo o que fosse necessário para produzir, e não dispor de homens habilidosos e experientes para erguer a indústria 
e levá-la à frente. Nessa situação, caso se empregue parte de seu capital material na formação do capital mental dos seus concidadãos, fazendo-lhes adquirir habilidades e competências na condução dos seus negócios, o dispêndio imediato de recursos para a instrução produzirá em breve espaço de tempo rentabilidade dez vezes maior do que os gastos. Sob tais condições, uma nação que investe na formação e desenvolvimento das suas forças produtivas, a princípio, tem um pequeno dispêndio. Essa despesa é ínfima se comparada com a expansão do poder produtivo da nação, e será depois de alguns anos várias vezes compensada pelos benefícios provenientes de uma economia nacional mais desenvolvida (LIST, 1909, p. 198).

Vale notar que após a impressão e difusão dos Outlines, List tornou-se imediatamente celebridade, recebendo cumprimentos das mais altas autoridades do país, sendo repetidamente citado a favor ou contra, por membros do Congresso (EARLE, 1943, p. 431). Os Outlines alcançaram repercussão tão ampla que List logo foi convidado a dar palestras para diversos membros do Congresso sobre os temas de suas cartas. Richard Rush, Secretário do Tesouro à época, que tinha sido anteriormente embaixador americano em Londres, destaca cortesmente a imensurável contribuição das cartas de List para esclarecer a questão inerente à proteção dos interesses nacionais (HIRST, 1909, p. 44). De fato, seus argumentos influenciaram sobremaneira o Congresso norte-americano a aprovar a Tariff of Abominations de 1828, fazendo List um dos responsáveis pela promoção das leis protecionistas que abriram o caminho à possibilidade de fomento à indústria nascente, lançando assim as bases para a industrialização dos Estados Unidos. ${ }^{15}$

15 Inicialmente, os Estados Unidos não tinham um sistema aduaneiro em nível federal. De fato, a primeira tentativa de proteção tarifária pelo Congresso em 1781 falhou. Quando adquiriu o poder para tributar, o Congresso aprovou uma lei tarifária bastante liberal (1789), outorgando uma tarifa fixa de $5 \%$ sobre todas as importações, com algumas exceções. Após a divulgação dos Reports de Hamilton, a tarifa média sobre os produtos manufaturados estrangeiros foi aumentada de $5 \%$ para $12,5 \%$, mas era demasiado baixa para induzir os americanos a comprarem bens manufaturados nacionais. Quando a guerra de 1812 eclodiu, o Congresso dobrou imediatamente as tarifas de importação de $12,5 \%$ para $25 \%$. Posteriormente, em 1816, as tarifas foram elevadas ainda mais, alcançando a média de 35\%. Em 1820, a tarifa média aumentou para 40\%, tal como estabelecera o programa de Hamilton (CHANG, 2007a, p. 25-26; 2007b, p. 34-35). Porém, segundo List, após a cessação das hostilidades, os laços entre os Estados da União eram muito fracos para dar proteção adequada à indústria e aos negócios que se desenvolveram enquanto o comércio com a Inglaterra tinha sido interrompido. Consequentemente, pressionado por poderosos interesses opostos aos dos manufatores nacionais, o Congresso aprovou medidas de considerável redução das taxas alfandegárias. Foi somente no ano de 1824, ou seja, depois que os efeitos das leis inglesas sobre a importação de cereais manifestaram-se em toda a sua extensão, que o Congresso aprovou tarifas mais elevadas. Em 1825, não obstante o Reino Unido aderir cada vez mais ao livre mercado, o número de falências entre os produtores americanos de trigo tinha crescido a um grau tão alarmante que o Congresso concordou em outro aumento na tarifa. Assim que as informações relativas aos novos tributos chegaram à Inglaterra, o parlamento inglês tomou medidas de retaliação contra os americanos. Essa represália colocou os fabricantes americanos em uma posição ainda pior do que antes, o que levou o Congresso a aprovar, em 1828, tarifas ainda superiores, elevando a taxa média dos bens tributáveisa 61\% do valor, depois, aliás, de debates violentos (LIST, 1983, p. 75 e 173; HUGHES, 1990, p. 154). 


\section{Sobre a Matriz do Pensamento Listiano}

Existe um debate não resolvido acerca da fonte de inspiração de List para a elaboração do seu Sistema. Alguns estudiosos salientam haver notável semelhança entre as teorias de List e Raymond. Charles Neill, por exemplo, argumenta que nos Thoughts on Political Economy de Raymond publicados em 1820, e em seus Elements of Political Economy (Elementos de Economia Política, 1823), encontram-se enunciados os princípios fundamentais que List tomou como base para a elaboração não apenas dos seus Outlines, mas também de sua obra mais completa, isto é, Das Nationale System der Politischen Ökonomie (Sistema Nacional de Economia Política, 1841) (NEILL, 1897, p. 47). Outros autores, como Margareth Hirst e Ha-Joo Chang, sugerem que List só adquiriu maturidade intelectual durante sua permanência nos Estados Unidos, mais precisamente quando do seu contato com o American System (HIRST, 1909, p. 117; CHANG, 2007a, p. 25-61; 2007b, p. 33).

De fato, parece inegável que List foi, em grande medida, influenciado pelo debate sobre as questões tarifárias nos Estados Unidos, país onde ele não apenas refinou seu instrumental teórico, mas também testemunhou na prática a importância do transporte ferroviário como meio de interligar o mercado nacional e promover a unidade das forças produtivas. ${ }^{16}$ Não se pode inferir disso, todavia, que List tenha mudado de ideia após o seu contato com os economistas americanos. Nesse sentido, importa lembrar que List se tornou digno da estima e admiração de homens da estatura de Andrew Jackson, John Quincy Adams, Henry C. Carey, Charles Ingersoll, entre outros, não apenas pelo fato de ter sido ele apresentado pelo célebre Marquis de Lafayette, mas principalmente pela circunstância de List, que ao chegar à América já era um homem dotado de aguda percepção dos princípios da administração pública e da vida econômica.

Nota-se que, a princípio, como era habitual nos territórios alemães na virada do século XIX, a devoção às ideias cosmopolitas e de liberdade universal apregoadas pelo Iluminismo e pelos liberais também deixaram fortes marcas no jovem List. Ele mesmo recordaria que por muitos anos foi não apenas um discípulo fiel de Smith e Jean-Baptiste Say, mas também zeloso professor da doutrina clássica, só mudando de opinião em virtude dos resultados positivos do bloqueio napoleônico para a indústria alemã, e os efeitos danosos subsequentes ao retorno do livre mercado após a queda de Napoleão (LIST, 1983, p. 4; LIST, 1909, p. 173). A proteção parcial contra a competição inglesa, segundo explicou List em seu Sistema

16 Como recorda List (1983, p. 5), "[...] quando visitei os Estados Unidos, pus de lado todos os livros pois a essa altura só tenderiam a desencaminhar-me da via certa. A melhor obra sobre Economia Política que se possa ler naquele país moderno é a vida real. Ali se pode observar como regiões selvagens se transformam em Estados ricos e poderosos [...]. Em lugar algum como lá se pode constatar a importância dos meios de comunicação e o seu efeito sobre a vida intelectual e material do povo". 
Nacional de Economia Política, desencadeou um progresso admirável não apenas nos diferentes setores da indústria alemã, mas também fez florescer todos os ramos da agricultura.

Quaisquer que sejam as alegações dos teóricos, particularmente dos ingleses, contra o bloqueio, é incontestável - e todos os que conhecem a indústria alemã devem atestá-lo, pois há testemunhas abundantes do fato em todos os escritos estatísticos da época - que, como resultado daquele bloqueio, as manufaturas alemãs de toda espécie, pela primeira vez, começaram a registrar progresso importante; que somente então tornou-se generalizada e bem-sucedida a criação mais aperfeiçoada de ovelhas (iniciada algum tempo antes); que somente então se trabalhou na melhoria dos meios de transporte (LIST, 1983, p. 64).

Apesar disso, continua List, “[...] em centenas de cátedras universitárias alemãs ensinou-se a doutrina de que as nações só conseguem chegar à riqueza e ao poder mediante o comércio livre, universal e sem restrições". Consequentemente, grande quantidade de bens manufaturados ingleses foram importados logo após o colapso do Sistema Continental, de modo que as indústrias que tinham se desenvolvido durante às guerras napoleônicas foram ameaçadas de extinção por causa da desigual concorrência (LIST, 1983, p. 9 e p. 261). O efeito imediato da assimilação da doutrina clássica foi que, depois de haver conquistado os campos e os mercados alemães, a Inglaterra converteu os territórios germânicos num mercado tão promissor quanto aquele por ela usufruído em seu comércio com a Índia e a China.

\begin{abstract}
A Inglaterra, não satisfeita em ter arruinado a maior parte das manufaturas alemãs e fornecer-lhes enormes quantidades de tecidos de algodão e lã, excluiu de seus portos os cereais e a madeira alemãs, e até, de tempos em tempos, a lã alemã. Houve tempo em que a exportação de manufaturados ingleses para a Alemanha era dez vezes maior do que a exportação feita ao seu tão enaltecido Império das Índias Orientais (LIST, 1983, p. 261).
\end{abstract}

Portanto, foi a contemplação dos efeitos perniciosos do livre comércio sobre a economia alemã que induziu List à dúvida sobre a infalibilidade do pensamento econômico inglês (LIST, 1983, p. 3). Em suas palavras:

Meus olhos não sendo afiados o suficiente para descobrir num relance os erros de um sistema tão engenhosamente construído e apoiado por tantas verdades valiosas, julguei a árvore pelos seus frutos. Percebi que, como uma teoria engenhosamente inventada na medicina e, por mais que, apoiada em verdades brilhantes, ela deve ser fundamentalmente errônea se destrói a vida de seus seguidores. Por isso, um sistema de economia política deve estar errado, se ele afeta apenas o contrário daquilo que todos os homens de bom senso devem supor esperar dele (LIST, 1909, p. 175). 
Importa lembrar ser nesse exato momento em que sucedeu a dominação napoleônica que List entrou em íntimo contato com o Historicismo e o Idealismo Alemão, sobretudo, durante sua permanência em Tübingen. Como se sabe a partir de meados do século XVIII, a História ocupou lugar de destaque nas especulações filosóficas alemãs, alcançando o seu ápice no sistema hegeliano. Decerto, o historicismo pode ser entendido como um fenômeno intelectual oposto ao universalismo e ao cosmopolitismo apregoados pelo Iluminismo, que exerceu influência determinante na formação do pensamento moderno alemão. Embora Herder já tivesse oferecido extensiva apresentação dos princípios do historicismo alemão, ${ }^{17}$ o fator mais importante que acelerou a transição do Iluminismo para a perspectiva historicista foi o impacto dos acontecimentos políticos de 1792 a 1815 (IGGERS, 1983, p. 38).

Muitos eruditos alemães buscaram na história o fundamento de sua tradição política. Por exemplo, em lugar do conceito utilitarista de Estado, como instrumento dos interesses e bem-estar de sua população, eles propunham enfaticamente o conceito idealista do Estado como fim em si mesmo. Nesse sentido, o Estado não deve ser julgado por padrões éticos externos ou por normas utilitárias, mas deve sempre ser guiado e julgado em termos de poder político. Além da esfera política, a História tornou-sea pedra angular daverdadeira cultura alemã. Aos poucos, a filosofia e a metodologia do historicismo permearam todas as ciências humanas e culturais alemães, de modo que a linguística, a filologia, a economia, a arte, o direito, a teologia etc. tornaram-se estudos orientados historicamente. Assim, a História veio a ser o único guia para o entendimento das coisas humanas, dominando a produção intelectual alemã por mais de um século (IGGERS, 1983, p. 15).

O próximo passo na consagração da História foi dado por um grupo seleto de filósofos sob a insígnia do Idealismo Alemão. Nesse caso, merecem destaque as contribuições de Friedrich Wilhelm Schelling (1775-1854) e, sobretudo, Georg Wilhelm Friedrich Hegel (1770-1831), para quem a História é, entre outras coisas, o desenvolvimento progressivo do espírito rumo à liberdade (FRANÇA, 2010, p. 76). Compreendendo o espírito como vida, e a vida humana como história, Hegel assevera que esta é na verdade o processo de formação da consciência. Nesse sentido, o indivíduo singular deve perpassar as fases de formação do espírito universal como etapas de um caminho já batido e pavimentado na larga extensão do tempo (HEGEL, 1987, p. 21-22). Desse modo, é através da percepção do processo histórico que se pode compreender não apenas as "leis da história", seu sentido e

17 Em 1774, Herder publicou sua obra Auch eine Philosophie der Geschichte zur Bildung der Menschheit (Filosofia da História para a Educação da Humanidade), onde comenta algumas de suas concepções acerca do processo histórico sob a perspectiva da diversidade e da transformação cultural. Posteriormente, suas ideias centrais sobre a História foram debatidas novamente em sua obra máxima, Ideen zur Philosophie der Geschichte der Menschheit (Ideia para a Filosofia da História da Humanidade, 1789-1791) (BUARQUE, 2003, p. 58). 
sua direção, mas, principalmente, entender nossa atual situação histórica (CORBISIER, 1991, p. 18).

Como exposto anteriormente, List foi professor em Tübingen durante o período em que o pensamento hegeliano alcançou o seu máximo esplendor, tornando-se hegemônico em praticamente todo o território alemão. De fato, List e Hegel tinham relação muito próxima. List havia cooperado com o filósofo alemão na elaboração da constituição para o Estado de Württemberg. Além disso, durante um ataque dos antimonarquistas, Hegel publicou sua defesa do rei Wilhelm I de Württemberg a pedido de List. Isso não somente mostra a conexão entre os dois, mas também o quanto eram partidários da ideia de unidade alemã e liberdade política (DAASTØL, 2011, p. 22). Nota-se que List assimilou de Hegel, entre outras coisas, a ideia segundo a qual a história é sumamente importante para a compreensão do presente. Na verdade, a história tornou-se o eixo condutor de toda a sua crítica do pensamento econômico clássico, sendo que através dela ele refuta os princípios de liberdade universal como condição necessária do crescimento econômico. Além disso, tal como em Hegel, List acredita que o fator determinante da mudança histórica seria, sem dúvida, o crescimento do espírito objetivo, isto é, o Estado, entendido como plena realização da racionalidade, do exercício da liberdade concreta, da moralidade e da inovação rumo ao progresso.

Com efeito, a História tornou-se para List o fundamento de um novo posicionamento em contraposição aos valores universais e liberalizantes da Inglaterra. Por isso, ela serve tanto para a comprovação de suas hipóteses, quanto para revelar as especificidades do processo de evolução econômica de cada povo (LIST; HODGSKIN, 1983, p. 6). Assim, através dos ensinamentos da História, List intenta destacar as causas do malogro econômico de diversas nações a fim de precaver a Alemanha dos efeitos perniciosos da fragmentação política e do livre comércio em se tratando de países que se encontram em retardo técnico-industrial. De fato, List vinha se ocupando há muito da questão concernente ao método histórico, o qual já tinha discutido, ainda que superficialmente, durante sua permanência nos Estados Unidos. Nos seus maiores trabalhos, tanto no Sistema Natural como no Sistema Nacional, List repetidas vezes compara países e situações ao longo da história, e enquanto julga e toma o devido conhecimento das diferentes circunstâncias e situações do passado, ele tenta entender os padrões de desenvolvimento econômico e formular tendências baseando-se em cuidadosas observações empíricas.

List afirma que suas investigações seguiram o método empírico e realista, no sentido de que o seu Sistema é baseado na experiência histórica, não sendo, portanto, um sistema abstrato com base em axiomas a priori. Ao contrário, ele fundou suas conclusões em príncipios derivados do que realmente acontece no mundo real. Com sua abordagem histórica, ele deu continuidade ao projeto hegeliano de que só o real é racional (DAASTØL, 2011, p. 68). Em seu ensaio sobre 
a reforma agrária, Die Ackerverfassung, die Zwergwirtschaft und die Auswanderung (Constituição Agrícola, Pequenos Negócios e Emigração, 1942), apesar de longo tempo ignorado, é talvez o primeiro trabalho sistemático na tradição histórica, isto é, com uma metodologia empírica, em oposição à metodologia abstrata da escola britânica clássica. Anteriormente, além de Die Freiheit und die Beschränkungen des Auswärtigen Handels, aus dem Historischen Gesichtspunkt be Leuchtet (A Liberdade e Restrições ao Comércio Exterior, Iluminado a partir de um Ponto de Vista Histórico, 1839), List sustentou, em um artigo intitulado L'Économie Politique devant le Tribunal de l'Historie (Economia Política no Tribunal da História, 1836,) que, uma vez que a economia, assim como a medicina, baseia-se na observação e na experiência, suas proposições devem ser encontradas na história (BOIANOVISKY, 2011, p. 7).

Esses e outros artigos não apenas exprimem o processo de gestação de um novo método de análise do pensamento econômico, eles também antecipam a abordagem histórica e os poderosos argumentos que serão expostos de forma cabal no Sistema Nacional de Economia Política, o que faz de List, em verdade, precursor da Escola Histórica Alemã. Com efeito, embora a experiência nos Estados Unidos tenha sido significativa no desenvolvimento das ideias econômicas de List, é evidente que ele havia mudado seu pensamento enquanto ainda vivia em Wüttermberg, isto é, baseando-se sobremaneira na experiência germânica.

\section{A Unidade Germânica no Binômio Listiano}

Durante sua atividade como editor ${ }^{18}$ do Württembergische Archive e no Volksfreund aus Schwaben, List lançou as bases da Zollverein (União Aduaneira Nacional dos Estados Alemães), alicerce da unidade econômica da futura nação alemã. Seu objetivo era abolir todas as tarifas aduaneiras internas entre os vários Estados germânicos e estabelecer um sistema comercial e alfandegário comum para toda a

18 List editou e contribuiu para os jornais: Württembergische Archive (tradução: Arquivo de Württemberg, 1817); Volksfreund aus Schwaben. Vater-lands-Blatt für Sitte, Recht und Freiheit, Stuttgart: Gesellschaft wahrheitliebender Württemberger (tradução: Amigo da Nação da Suábia, 18181821); Der Readinger Adler, Reading [Pa.: J. Schneider, 1801-1854 (tradução: A Águia Leitora, 1826); Encyklopaedie der Staatswissenschaften, Altona: J. F. Hammerich (Aka: „Rotteck-Welckersches Staatslexicon $\square$ ) (tradução: Enciclopédia das Ciências Políticas, 1834); Das National-Magazin der Gesellschaft zur Verbreitung gemeinnütziger Kenntnisse, Leipzig: Gesellschaft zur Verbreitung Gemeinnütziger Kenntnisse (tradução: A Revista Nacional da Sociedade para a Difusão do Conhecimento de Utilidade Pública, 1834); Eisenbahn-Journal und National-Magazin für die Fortschritte im Handel, Gewerbe und Ackerbau, für National-Unternehmungen und öffentliche Anstalten, für statistische Nachrichten und neue Entdeckungen jeder Art und für interessante Erscheinungen in der Literatur und Praxis der Nationalökonomie überhaupt. Altona: (tradução: Revista da Ferrovia e Revista Nacional para Invenções, Descobertas e Progresso no Comércio, Indústria, Entendimento Público, Instituições Públicas, Estatística para descoberta deNovas Invençõesde qualquer tipo epara os fenômenosinteressantes naliteratura e na Práticada Economia Nacionalemgeral, 18351837). Além disso, a maior parte dos 650 artigos do Zollvereinsblatt foi escrito por List (tradução: Zollverein Gazeta, 1843-1846). 
Alemanha. ${ }^{19}$ Certamente, ele percebeu que, ante ao fortalecimento da Inglaterra e da França como países industrializados e com império em expansão, bem como a reafirmação da Áustria e da Rússia como potências imperiais após o Congresso de Viena, somente a extinção das fronteiras que até então dividiam e enfraqueciam os territórios germânicos poderia suprimir a fragmentação política e o retardo técnico-industrial dos Estados Alemães. Desse modo, List se engajou no estabelecimento deuma nova sociedadepara o comércioe indústria, ou seja, a "Liga Alemã do Comércio e Indústria" (Deutsche Handels-und Gerwerbeverein), tornando-se seu "secretário consular" (DAASTØL, 2011, p. 24).

Em abril de 1819, em uma viagem de férias para Göttingen, List visitou Frankfurt-on-Meno, no momento da Feira de Páscoa, quando a cidade estava repleta de comerciantes e fabricantes de todas as partes da Alemanha. Ali, List reuniu um grande número de homens de negócios para discutir não apenas propostas para abolir todas as alfândegas internas, mas também a possibilidade de criação de um sistema único de tarifas alfandegárias para toda a Alemanha (SNYDER, 1978, p. 19). Posteriormente, em setembro de 1820, um Congresso Comercial reuniu em Darmstadt representantes de todos os Estados do Sul, Prússia e Saxônia. Formou-se, assim, um comitê composto por comerciantes de Reno, Prússia, Baviera, Saxônia, Württemberg, Nassau e Baden. Além disso, convites para juntar-se à nova liga foram enviados para as comunidades comerciais de Hanover, Brunswick, Leipzig e as cidades hanseáticas (LIST, 1983, p. 1-2; HIRST, 1909, p. 15-19).

Como recorda posteriormente em seu Sistema Nacional de Economia Política,

Os artigos de sua constituição foram submetidos à Dieta, bem como a todos os governantes dos Estados germânicos, para aprovação. Em cada cidade alemã foi nomeado um correspondente local, e todo Estado alemão tinha o seu correspondente provincial. Todos os membros e correspondentes obrigavam-se a promover a consecução dos objetivos da associação com todos os meios disponíveis. A cidade de Nuremberg foi escolhida como quartel-general da associação, sendo autorizada a nomear uma comissão central, à qual caberia dirigir os negócios da associação, sob a orientação de um assessor, cabendo esta última função ao autor da presente obra. [...] Depois de essa associação apresentar à Dieta germânica uma petição, encarecendo a necessidade e a conveniência das medidas propostas pela sua organização, a comissão central de Nuremberg deu início às suas operações. Delegações foram enviadas a todas as cortes germânicas, enviando-se também uma ao congresso geral realizado em Viena em 1820. Naquele congresso conseguiu-se, no

19 Em 1819, a Alemanha inteira fervilhava de esquemas e projetos de novas instituições políticas. O próprio artigo XIX da Constituição da nova Dieta deixava expressamente aberta a porta para o estabelecimento de um sistema comercial nacional. Segundo List (1983, p. 4), "[...] esse artigo pareceu-me oferecer uma base sobre a qual poderia assentar a futura prosperidade comercial e industrial da nossa pátria alemã, surgindo daqui a ideia de fundar uma liga de comerciantes e manufatores alemães para a abolição de nossas tarifas internas e a adoção de uma política comercial comum para toda a Alemanha." 
mínimo, um resultado: vários Estados germânicos menores e de segunda categoria concordaram em realizar um congresso especial sobre o assunto, em Darmstadt. O efeito das deliberações desse último congresso foi, primeiramente, realizar uma união entre Württemberg e a Baviera; em segundo lugar, uma união de alguns Estados germânicos com a Prússia; a seguir, uma união entre os Estados alemães médios; e, finalmente, sobretudo em conseqüência da atuação do Freiherr Von Cotta, fundir as três uniões acima mencionadas em uma confederação alfandegária geral, de sorte que, no momento atual, se excetuarmos a Áustria, as duas Mecklenburgo, Hanover e as cidades da Liga Hanseática, a Alemanha inteira está unida em uma só Associação Alfandegária, a qual aboliu as alfândegas existentes entre um estado e o outro, estabelecendo também tarifas uniformes e unitárias comuns em relação aos produtos estrangeiros, sendo que a renda proveniente da cobrança dessas tarifas aduaneiras é distribuída proporcionalmente entre os diversos Estados alemães, de acordo com a população de cada um [...] (LIST, 1983, p. 66).

Enquanto List estava em exílio nos Estados Unidos, a Zollverein progrediu, ainda que lentamente. No ano de 1828, dois "Zollvereins" foram formados, um entre Württemberg e Baviera, o outro entre a Prússia e Hesse. Essas duas ligas preparam o caminho de transição para um sistema mais amplo. Em 1829, a liga Bavária-Württemberg instituiu um tratado comercial com a Prússia e Hesse, que estabeleceu o livre comércio prático entre os quatro Estados Alemães. Por outro lado, a Saxônia era o maior obstáculo para qualquer avanço; e por mais algum tempo, sobretudo por motivos políticos, ela se recusou a entrar em qualquer tratado com a Prússia. Somente em $1^{\circ}$ de janeiro de 1834, uma Zollverein alemã foi formada entre a Prússia, Nassau, Württemberg, Baviera, Saxônia e os Estados da Turingia. Na verdade, estes últimos se juntaram somente no decorrer dos próximos dois anos, através de Baden, Nassau e da cidade de Frankfurt (HIRST, 1909, p. 19).

Imediatamente após se tornar cidadão americano, naturalizado em outubro de 1830, List teve uma entrevista com o presidente Andrew Jackson e pediu-lhe para ser nomeado cônsul americano na Saxônia, Baviera, Hesse Kassel, e Alsácia. Sempre pronto para recompensar os seus apoiadores, Jackson nomeou List cônsul americano em Hamburgo, sujeito a confirmação pelo Senado. ${ }^{20}$ List, contudo, não assumiu as suas funções em Hamburgo. Seus adversários no senado americano partidários do livre comércio - trabalharam pelo indeferimento de sua nomeação (HENDERSON, 2006, p. 72).

Em julho de 1832, List foi nomeado cônsul americano em Baden e, no ano seguinte, quando avançavam as negociações da Zollverein formada entre a Prússia, Nassau, Württemberg, Baviera, Saxônia, e os Estados da Turingia, List obteve

20 List apoiou Andrew Jackson em sua campanha à presidência dos Estados Unidos de 1828, inclusive usando de sua influência editorial na Adler em benefício do candidato. Importa lembrar que o apoio dos imigrantes alemães na Pensilvânia foi fator determinante na eleição de Jackson, já que os percentuais de votos para John Quincy Adams no Leste e para Jackson no Sul foram praticamente iguais (BELL, 1942, p. 78; EARLE, 1943, p. 431). 
consulado em Leipzig (HIRST, 1909, p. 19). No entanto, ele não dedicou muito tempo aos deveres inerentes a esse cargo, ocupando-se quase que integralmente dos assuntos referentes à união aduaneira. Nesse ínterim, ele defendeu não somente a expansão da união aduaneira para incluir os Estados Alemães que ainda não tinham aderido, mas também a adoção de uma política protecionista. ${ }^{21}$ Em sua opinião, um grande erro tinha sido feito em 1834 quando os Estados Alemães aderiram à Zollverein concordando em adotar a tarifa prussiana de 1818, a qual, naquela época, era a mais liberal na Europa (LIST, 1983, p. 1-2; HENDERSON, 2006, p. 90).

Ainda em 1835, ele fundou um jornal técnico especializado em estradas de ferro intitulado Eisenbahn-Journal (Revista da Ferrovia), ${ }^{22}$ dando considerável atenção à possibilidade de interligar os estados alemães (Deutscher Zollverein) por meio das linhas férreas. Com efeito, durante 1833-1837, List elaborou projetos detalhados para ferrovias na Prússia, Hamburgo, Braunschweig e Baden. Além disso, projetou uma rede ferroviária para a Saxônia (Über ein sächsisches Eisenbahn-System als Grundlage eines allgemeinen deutschen Eisenbahn-Systems), que também serviu de base para interligar Leipzig-Dresden. Em 1836, ele esboçou um projeto de estrada de ferro de Mannheim a Basiléia (Memoire die Eisenbahn von Mannheim nach Basel betreffend), de modo que, em 1837, foi convidado a participar da construção da primeira ferrovia alemã e uma das primeiras no continente europeu (DAASTØL, 2011, p. 28).

De fato, todos os esforços em prol da construção de estradas de ferro levados a efeito por List para a Alemanha desde 1833 estavam ligados, de certo modo, ao seu projeto de unidade e grandeza alemã. O sistema ferroviário alemão e o Zollverein seriam faces opostas de uma mesma moeda (EARLE, 1943, p. 442). Sem o Zollverein, nenhum sistema ferroviário alemão jamais seria sequer discutido, muito menos construído. Por outro lado, somente por intermédio de um sistema ferroviário alemão seria possível promover a unidade das forças produtivas, alavancando, assim, as potencialidades da nação. Além disso, List dedicou-se à construção de estradas de ferro, pois, em seu entendimento, apenas por intermédio de meios eficientes de transporte cada distrito ou província poderia transferir a sua produção para as outras províncias, até mesmo para as mais distantes, obtendo em troca os produtos excedentes de tais regiões. Se não houvesse estradas, canais e trens, não

21 List reconhece as vantagens gerais do comércio internacional livre, mas prefere limitar seu impacto a países com grau semelhante de desenvolvimento. De fato, ele acreditava que restrições comerciais temporárias, além de outras medidas, deveriam servir para nivelar as diferenças entre parceiros comerciais em diferentes estágios de desenvolvimento (WENDLER, 2013, p. 224).

22 National-Magazin für neue Erfindungen, Entdeckungen und Fortschritte im Handel und Gewerbe, in der Land- und Hauswirthschaft, in öffentlichen Unternehmungen und Anstalten, sowie für Statistik, Nationalökonomie und Finanzwesen (Revista Nacional de Invenções, Descobertas e Progresso no Comércio, Indústria, Entendimento Público e Instituições Públicas, e de Estatística e Economia Nacional e Finanças). 
haveria mercados; e sem indústria, os agricultores ainda seriam camponeses. Assim, as ferrovias e a infraestrutura não somente trazem consigo o poder da ciência, mas também industrializam todas as partes do país, rompendo e transformando os modos de vida pastoris com as atividades mais cultas e educadas da vida urbana (FREEMAN; BOWENED, 2008, p. 58).

Em 1838, List publica um trabalho sob o título Das Deutsche National-Transport-System in Volks-und Staatswirthschaftlicher Beziehung (Aspectos Politicos e Econômicos de um Sistema Germânico de Transporte), o qual foi originalmente impresso como um longo artigo na Staatslexikon. Em 1839, ele publicou uma obra intitulada Das Wesen und der Wert einer nationalen Gewerbsproduktivkraft (A Natureza e o Valor da Força Produtiva de uma Nação), e iniciou a elaboração de sua obra mais importante, ou seja, Das Nationale System der Politischen Ökonomie (DAASTØL, 2011, p. 29).

Durante muito tempo, List viajou por praticamente todos os estados alemães difundindo suas ideias. Visitou muitos líderes políticos e chefes de Estado como Anthonie, o rei da Saxônia (1833); o rei Ludwig I da Baviera (1841); o príncipe Maximiliano da Baviera (1842); o ministro das finanças da Rússia, George von Cancrin (1843); o ministro do Interior, príncipe von Öttingen da Baviera-Wallerstein (1845); o príncipe Karl von Leiningen (1845), um meio-irmão da rainha Victoria da Grã-Bretanha. Além disso, List encontrou-se com homens de ciência e das artes como Alexander von Humboldt (1834), Klara Wieck-Schumann (1840), além de Heine e Börne, já mencionados. Em sua visita a Londres, pouco antes de morrer, ele conheceu o príncipe Albert da Grã-Bretanha (1846); os comerciantes Richard Cobden (1846), John Bowring (1846) e John Ramsay MacCulloch, bem como o futuro primeiro ministro Lord Palmerston (1846) (DAAST ØL, 2011, p. 28).

Por volta de 1844-45, List viajou pela Áustria e diversos estados alemães divulgando suas ideias. Contudo, ele já contava inúmeros inimigos poderosos. Em consequência disso, em 1846, doente e com sua saúde física e mental debilitada, durante uma viagem para promover a criação da Sociedade de Indústria e Comércio da Baviera, no dia 30 de novembro, em Kufstein, List se suicidou com um tiro no peito, encerrando aos 57 anos sua intensa carreira em prol da unidade alemã (LEVI-FAUR, 2012, p. 156). Menos de um ano depois de sua morte, foi convocada a Dieta Unida para discutir a unificação da Alemanha, e, em 1848, iniciaram-se os trabalhos de uma Constituinte Nacional, culminando, posteriormente, na consolidação do Estado alemão como nação política e economicamente desenvolvida, cortada por estradas de ferro que seguiam muito aproximadamente o traçado que List havia proposto, tomando-se como referência as suas propostas, desde 1819, quando sugeriu a criação da União Alemã de Comércio e Indústria. Dez anos depois de sua morte, o mapa político alemão era cortado por estradas de ferro que seguiam aproximadamente o traçado que List havia proposto em um dos seus 
projetos de unificação política para a Alemanha (FURNISS, 1909, p. 434). Pouco depois, quando se tornou óbvio que suas ideias de economia nacional prestavam, na realidade, um magnífico serviço à sua pátria, o homem que tinha sido violentamente denunciado durantea sua vida, agora foi exaltado como um verdadeiro patriota $^{23}$ (SNYDER, 1978, p. 6).

\section{Considerações Finais}

A formação e o desenvolvimento do pensamento de List se processaram em um contexto de significativas transformações políticas e econômicas provocadas, sobretudo, pelos fenômenos do Iluminismo, da Revolução Francesa, da ocupação napoleônica e da Revolução Industrial. Sua experiência como burocrata não apenas colocou-o em contato direto com as questões tarifárias e de finanças, mas também com a negligência e improbidade no serviço público. Após a morte de seu irmão Johannes ${ }^{24}$ (1787-1813), seguida da morte de seu pai e logo depois a perda de sua mãe, ${ }^{25}$ List iniciou intensa atividade jornalística em defesa da probidade administrativa. Em seguida, lançando mão de sua experiência na administração pública, List passou a defender medidas protecionistas e de união aduaneira.

A proteção concedida às indústrias alemãs durante a ocupação napoleônica e os efeitos da introdução do livre mercado proporcionaram a List o conteúdo empírico para colocar em questão a teoria do livre comércio da escola clássica. Sua estadia nos Estados Unidos não apenas reforçou suas ideias de unidade econômica e poderio nacional, mas também lhe inseriu no riquíssimo debate sobre tarifas al-

23 Em Reutlingen há uma estátua de Friedrich List na praça em frente à estação ferroviária. Espaço considerável é dedicado a List no Museu de História Local, enquanto todos os seus arquivos são preservados na sede da prefeitura. A antiga cidade imperial homenageia o homem que, depois de representá-la no parlamento de Württemberg, projetou seu nome para além das muralhas da cidade natal, como um patriota que defendeu a causa da unidade alemã num momento em que o país estava dividido em muitos estados (HENDERSON, 2006, p. 1).

24 Em 1806, o rei Friedrich I determinou que todos os homens susceptíveis de serviço militar fossem registrados, mas quem tivesse 25 anos de idade e casado poderia ser isento do serviço obrigatório. Visto que um novo alistamento era iminente, Johannes, com 26 anos na época, decidiu se casar. Para tanto, ele precisava fazer o registro adequado no escritório do distrito de Reutlingen. A pessoa responsável, um funcionário nomeado que tinha sido transferido para Reutlingen pelo governo de Württemberg em 1810, disse a Johannes que o registro estava em Stuttgard e que ele teria que fazer lá, a fim de obter a dispensa. Após sofrer uma tentativa de suborno em troca do documento, Johannes viajou às pressas para Stuttgard. Durante a viagem, ele teve uma queda tão séria que morreu dois dias depois, antes de chegar a Reutlingen, como resultado de uma lesão espinhal. Sua morte foi um duro golpe para a família, em particular porque ele havia sido designado sucessor para o negócio de seu pai. O pai de List sofreu tão grande pesar pela morte do filho que ele, também, morreu seis meses depois, aos 68 anos de idade (WENDLER, 2013, p. 11).

25 A mãe de List morreu inesperadamente em 21 de março de 1815. Como ela não tinha seguido um decreto menor das autoridades do distrito a respeito de sua herança após a morte do marido, ela foi detida pela polícia e levada para a repartição distrital, onde foi tratada como criminosa. A senhora List foi tão afetada por esse tratamento indigno que morreu poucas semanas depois de um colapso nervoso (WENDLER, 2013, p. 11). 
fandegárias deste país. Nesse sentido, a contribuição de List em seus Outlines resulta, em certa medida, do contato com o Sistema Americano, mas também, e talvez principalmente, de suas experiências anteriores, sobretudo o seu conceito de nação e de unidade econômica. Com efeito, o maior legado dos Estados Unidos para List foi o conhecimento técnico sobre a construção de estradas de ferro. A partir de então, List elaborou um completo estudo que se transformou, posteriormente, em verdadeiro anteprojeto de um sistema nacional de transporte ferroviário visando integrar econômica e politicamente toda a Alemanha.

\section{Referências}

BELL, J. F. Frederick List, champion of industrial capitalism. The Pensilvânia Magazine of History and Biography, v. 66, n. 1, p. 56-83, 1942.

BENTO, L. C. Historicismo e história: a especificidade do conceito de sentido histórico em Herder e Droysen. In: BENTO, L. C. (Org.). História e ensino de história: as perspectivas do saber histórico e sua culminância para o desenvolvimento de um projeto de homem. Jundiaí: Paco Editorial, 2010. p. 13-25.

BERLIN, I. Vico and Herder: two studies in the history of ideas. London: Chatto $\mathcal{Z}$ Windus, 1976.

BOIANOVSKY, M. Friedrich List and the economic fate of tropical countries. History of Political Economy, v. 45, n. 4, p. 1-52, 2011.

BUARQUE, V. C. Fundamentos para uma história da diversidade e da transformação cultural: a obra de J. G. Herder. Encontros, v. 1, n. 1, p. 85-61, 2003.

CHANG, H. Bad Samaritans: the myth of free trade and the secret history of capitalism. London: Bloomsbury Press, 2007a.

. Kicking away the ladder: development strategy in historical perspective. London: Anthem Press, 2007b.

CHEVALLIER, J. J. As grandes obras políticas de Maquiavel a nossos dias. Rio de Janeiro: Agir, 1995.

CORBISIER, R. Hegel: textos escolhidos. Rio de Janeiro: Civilização Brasileira, 1991.

DAAST ØL, A. Friedrich List's heart, wit and will: mental capital as the productive force of progress. 2011. 583f. - Staatswissenschaftliche Fakultät, Universität Erfurt, Erfurt. 2011.

EARLE, E. M. Friedrich List, forerunner of Pan-Germanism. The American Scholar, v. 12, n. 4, p. 430-443, 1943.

FERRER, D. O nacionalismo de Fichte e a transformação da doutrina da ciência. Revista Filosófica de Coimbra, Lisboa, n. 17, p. 97-119, 2000.

FICHTE, J. G. Adresses to the German Nation. New York: Cambridge University Press, 2009. Publicado originalmente em 1808. 
FORREST, A.; WILSON, P. H. (Org.) The bee and the eagle: Napoleonic France and the end of the holy Roman empire, 1806. Basingstoke: Palgrave Macmillan, 2009.

FRANÇA, L. M. Hegel, o movimento especulativo do espírito e a história. Revista Simbiologias, v. 3, n. 5, p. 75-89, 2010.

FREEMAN, L. Economic wealth flows from the mind. Fidelio, v. 6, n. 1, p. 95-97, 1997.

FREEMAN, L.; BOWEN, M. The legacy of Friedrich List: the American system's battle against british free trade. The American Patriot, p. 56-59, Jan. 2008.

FURNISS, H. Life of Frieddrich List, and selections from his writings by Margaret E. Hirst and F. W. Hirst. The Economic Journal, v. 19, n. 75, p. 432-435, 1909.

HEGEL, G. F. W. Fenomenología del espíritu. Ciudad del México: Fondo de Cultura Económica, 1987. Publicado originalmente em 1807.

HENDERSON, W. O. Friedrich List: economist and visionary 1789- 1846. New York: Frank Cass and Company Limited, 2006.

HERDER, J. G. Filosofía de la historia para la educación de la humanidad. Buenos Aires: Editorial Nova, 2007.

HIRST, M. E. Life of Friedrich List and selections from his writings. London: Smith, Elder $\mathcal{3}$ CO., 1909.

HUGHES, J. American economic history. Evanston: Harper Collins Publishers, 1990.

IGGERS, G. G. The German conception of history: the national tradition of historical thought from herder to the present. Middletown: Wesleyan University Press, 1983.

KLEINGELDS, P. Six varieties of cosmopolitism in late eighteenth-century Germany. Journal of the History of Ideas, v. 60, n. 3, p. 505-524, 1999.

LEVI-FAUR, D. Economic nationalism: from Friedrich List to Robert Reich. Review of International Studies, v. 23, n. 3, p. 359-370, 1997.

. Friedrich List and the political economy of the nation-state. Review of International Political Economy, v. 4, n. 1, p. 157-178, 2012.

LEVINGER, M. Enlightened nationalism: the transformation of Prussia political culture (18061848). New York: Oxford University Press, 2000.

LIST, F. Outlines of American political economy. In: HIRST, M. E. Life of Friedrich List and selections from his writings. London: Smith, Elder E Co., 1909. p. 147-272. Publicado originalmente em 1827.

LIST, F. Sistema nacional de economia política. São Paulo: Abril Cultural, 1983. (Os Economistas). Publicado originalmente em 1841.

NEILL, C. P. Daniel Raymond: an early chapter in the history of economic theory in the United States. Baltimore: The Johns Hopkins Press, 1897. 
POPULATION COUNCIL. Friedrich List on globalization versus the national interest. Population and Development Review, v. 33, n. 3, p. 593-605, 2007.

RAYMOND, D. Thoughts on political economy, in two parts. American Review and Miscellaneous Journal, v. 12, n. 31, p. 443-466, 1821.

ROWE, M. The political culture of the holy Roman Empire on the even of its destruction. In: FORREST, A.; WILSON, P. H. (Org.). The bee and the Eagle: Napoleonic France and the End of the Holy Roman Empire, 1806. Basingstoke: Palgrave Macmillan, 2009. p. 42-64.

SCHUMPETER, J. A. História da Análise Econômica. Rio de Janeiro: Fundo de Cultura, 1964.

SNYDER. L. L. Roots of German nationalism. Bloomington: Indiana University Press, 1978.

WENDLER, E. Friedrich List (1789-1846): a visionary economist with social responsibility. Wiesbaden: Springer-Fachmedien, 2013.

ZANK, W. Nation, customs union, political union: collective identity, economy, and politics in Germany 1771-1871 in a non-structualist perspective. Aalborg: European Research Unit, Alborg University, 1994.

Recebido em: 20/07/2015. Aceito em: 28/10/2015. 